\title{
Preparation and Characterization of an Oral Vaccine Formulation Using Electrosprayed Chitosan Microparticles
}

Moreno, Jorge Alberto Sevilla; Panou, Danai-Anastasia; Stephansen, Karen; Chronakis, Ioannis S; Boisen, Anja; Mendes, Ana Carina Loureiro; Nielsen, Line Hagner

\section{Published in:}

AAPS PharmSciTech

Link to article, DOI:

10.1208/s12249-018-1190-1

Publication date:

2018

Document Version

Peer reviewed version

Link back to DTU Orbit

Citation (APA):

Moreno, J. A. S., Panou, D-A., Stephansen, K., Chronakis, I. S., Boisen, A., Mendes, A. C. L., \& Nielsen, L. H. (2018). Preparation and Characterization of an Oral Vaccine Formulation Úsing Electrosprayed Chitosan Microparticles. AAPS PharmSciTech, 19(8), 3770-3777. https://doi.org/10.1208/s12249-018-1190-1

\section{General rights}

Copyright and moral rights for the publications made accessible in the public portal are retained by the authors and/or other copyright owners and it is a condition of accessing publications that users recognise and abide by the legal requirements associated with these rights.

- Users may download and print one copy of any publication from the public portal for the purpose of private study or research.

- You may not further distribute the material or use it for any profit-making activity or commercial gain

- You may freely distribute the URL identifying the publication in the public portal 


\section{Preparation and characterization of an oral vaccine formulation using electrosprayed chitosan microparticles}

Jorge Alberto S. Moreno ${ }^{1,2}$, Danai-Anastasia Panou ${ }^{1}$, Karen Stephansen ${ }^{2}$, Ioannis S Chronakis ${ }^{2}$, Anja Boisen ${ }^{1}$, Ana C. Mendes ${ }^{2,3}$, Line Hagner Nielsen ${ }^{1}$

${ }^{1}$ Department of Micro- and Nanotechnology, Technical University of Denmark, Ørsteds Plads 345C, 2800 Kgs. Lyngby Denmark

${ }^{2}$ Nano-Bio Science Research Group, DTU-Food, Technical University of Denmark, Kemitorvet 202, 2800 Kgs. Lyngby, Denmark

${ }^{3}$ To whom correspondence should be addressed (e-mail: anac@food.dtu.dk ) 


\begin{abstract}
:
Chitosan particles loaded with the antigen ovalbumin (OVA) and the adjuvant, Quil-A were produced by electrospray, using mixtures of water/ethanol/acetic acid as a solvent. Three different chitosan's designed as $\mathrm{HMC}^{+} 70, \mathrm{HMC}^{+} 85$ and $\mathrm{HMC}^{+} 90$ (designated as 705010, 855010 and 905010) were tested and its efficacy to be used in oral vaccine delivery applications was investigated. The morphology, size and zeta potential of the produced particles were investigated, together with the encapsulation efficiency and release of OVA from the three chitosan formulations. Moreover, the mucoadhesion and cytotoxicity the chitosan microparticles was examined. All the three formulations with OVA and Quil-A were in the micrometer size range and had a positive zeta potential between 46 to $75 \mathrm{mV}$. Furthermore, all the three formulations displayed encapsulation efficiencies above $80 \%$ and the release of OVA over a period of $80 \mathrm{~h}$ was observed to be between 38-47 \%. None of the developed formulations exhibited high mucoadhesive properties, either cytotoxicity. The formulation prepared with $\mathrm{HMC}^{+} 70$, OVA and Quil-A had the highest stability within $2 \mathrm{~h}$ in buffer solution, as measured by dynamic light scattering. The electrosprayed formulation consisting of $\mathrm{HMC}^{+} 70$ with OVA and Quil-A showed to be the most promising as an oral vaccine system.
\end{abstract}

Keywords: Electrohydrodynamics, Polysaccharide, Particles, Ovalbumin, Quil-A 


\section{INTRODUCTION}

The discovery of vaccination has played a significant role for the public health in the world. Even though vaccination has decreased the morbidity and mortality from many diseases, there are still many infectious diseases remaining and therefore vaccination is a topic in continuous development(1).

Today, most vaccines are injected into the body, but it will create many advantages such as better patient compliance and increased safety, if oral vaccines can be developed(2,3). The absorptive area after oral administration is the intestinal epithelium, and its large surface area, typically makes it an ideal target. Although, for vaccines significant challenges are associated with oral delivery due to obstacles as poor stability of the vaccine formulation in the gastro-intestinal (GI) tract, low gastric $\mathrm{pH}$ and degrading enzymes. Thereby, making oral vaccine delivery extremely challenging(3).

Inactivated bacteria or viruses have been the traditional way of producing vaccines for decades, and even though these lead to high immunogenicity, they also carry much risk using them. Therefore, now-a-days subunit antigens are tended to be used, and as they are well-defined compounds of pathogens, they comprise high safety(1). On the other hand, these antigens are not as immunogenic as the whole pathogen, and therefore adjuvants need to be delivered together with the antigen(4). Adjuvants are structurally heterogeneous compounds that can potentiate an immune response, and in addition also induce a faster response(5). Furthermore, for oral vaccine delivery, a particulate system needs to encapsulate the antigen and adjuvant, as soluble antigens are scarcely immunogenic. The particles will further also protect the antigen through hostile environment of the GI tract and ensure presentation of the antigen to antigenpresenting cells after uptake in the small intestine(6-8). There are many promising delivery systems for this purpose, and chitosan nano- or microparticles are one of them $(9,10)$.

Chitosan is derived from the naturally occurring polysaccharide chitin(11), and is a biodegradable cationic biopolymer. Moreover, chitosan is also hydrophilic and $\mathrm{pH}$-sensitive(11). Due to the strong cationic properties, chitosan is proven to be mucoadhesive mainly due to the electrostatic interactions between positively charged chitosan and the negatively charged mucins in the mucus (e.g. found in the small intestine)(12). The mucoadhesion provides longer residence time in the intestine and thereby, enhance the delivery of the particles to reach the microfold (M) cells, where the vaccine formulation should be taken up. Furthermore, an important feature for chitosan particles is that they have been found to have adjuvant properties in itself(13).

There are many methods for producing chitosan microparticles as e.g. spray drying and cross-linking methods(14), but electrohydrodynamic techniques such as electrospray have shown advantages such as high loading efficiency $(15,16)$. In addition, it can be a very useful method for vaccine applications as electrospray is a gentle method without use of harsh solvents, and has shown not to degrade proteins and peptides during the particle production $(17,18)$. Moreover, the morphology and particle size can be adjusted through varying the process parameters and the choice of the materials and thereby electrospray has been reported as a versatile method, also for producing chitosan particles $(15,19,20)$. Previously, electrospray has been used to produce a vaccine formulation with microparticles of acetylated dextran encapsulating a subunit antigen, and this process resulted in an increased protection of the antigen $(18,21)$. Furthermore modified chitosan has been used for coating of calcium-alginate particles where the model subunit antigen ovalbumin (OVA) was encapsulated by the method of electrospraying $(22,23)$. 
In our previous study, chitosan electrosprayed microparticles were produced and optimized for oral drug delivery(24). Chitosan's with different molecular weight, degree of deacetylation (DD) and polymerization (DP), together with the different solvent compositions were investigated. It was found that stable chitosan particles in aqueous solutions with average size of approximately $1 \mu \mathrm{m}$ were produced by dissolving $3 \%$ $\mathrm{w} / \mathrm{v}$ of low molecular weight (28-49 $\mathrm{KDa})$ chitosan in mixtures of aqueous acetic acid and ethanol $50 / 50 \%$ $\mathrm{v} / \mathrm{v})$. Furthermore, these microparticles had good mucoadhesive properties showing its potential as a drug delivery carrier for this application of oral vaccine delivery(24).

The aim of this paper was to develop chitosan microparticles loaded with the subunit model antigen, OVA and the adjuvant, Quil-A using electrospraying as the encapsulation technique. Furthermore, the particles were in vitro characterized and tested for their cytotoxicity using THP-1 cells.

\section{MATERIALS AND METHODS}

\section{Materials}

Chitosan HMC 70/5 (MW 81 kDa, DD 88 \%), HMC 85/5 (MW 18 kDa, DD 94 \%) and HMC 90/10 (MW 28 kDa, DD 97 \%) were supplied by Heppe Medical Chitosan (HMC) GmbH (Halle, Germany). OVA (grade VII, from chicken egg white), phosphate buffer solution (PBS) tablets and fluorescein isothiocyanate (FITC - isomer I) were purchased from Sigma-Aldrich (St. Louis, MO, USA). Quil-A was acquired from Brenntag Biosector (Frederikssund, Denmark). Fasted state simulated intestinal fluids (FaSSIF) were obtained from Biorelevant.com (London, UK), while phorbol myristate acetate (PMA) was from Sigma-Aldrich (München, Germany). Ethanol 96 \% (EtOH) was acquired from VWR International (Darmstadt, Germany), and acetic acid (AA) $>99 \%$, stomach porcine mucin, periodic acid and Schiff's reagent for aldehydes were supplied from Sigma-Aldrich (Steinheim, Germany). RPMI 1640 was obtained from Gibco (Carlsbad, CA, USA), and $V_{y} B$ rant $^{\mathrm{TM}}$ CFDA SE Cell Tracer Kit was from Thermo Fisher (Waltham, USA). Lipopolysaccharides (LPS) from Salmonella enterica serotype enteritidis and Triton X-100 were purchased from Sigma-Aldrich (St. Louis, MO, USA). Paraformaldehyde was obtained from Electron Microscopy Sciences (Hatfield, USA), whereas milliQ water (Millipore Corporation, Billerica, MA, USA) was freshly produced in all cases.

\section{Preparation of Solutions for Electrospraying Chitosan Particles}

For the preparation of the chitosan particles with OVA and Quil-A, a similar method was used as described in the literature(24), but in this study with the addition of antigen and adjuvant to the particles. Here, 150 $\mathrm{mg}$ of OVA and $15 \mathrm{mg}$ of Quil-A were diluted in $4.5 \mathrm{~mL}$ of water, then $0.3 \mathrm{~g}$ of chitosan was dispersed, followed by the addition of $0.5 \mathrm{~mL}$ of $\mathrm{AA}$ in the case of $\mathrm{HMC}^{+} 70 / 5$ and $\mathrm{HMC}^{+} 85 / 5$, while for $\mathrm{HMC}^{+} 90 / 10,3.5$ $\mathrm{mL}$ of water and $1.5 \mathrm{~mL}$ of $\mathrm{AA}$ were added. The solutions were stirred until obtaining a homogenous mixture. Subsequently, $5 \mathrm{~mL}$ of ethanol were added and vortexed until obtaining a homogenous solution. The final concentration of chitosan was $3 \%(w / v)$. The nomenclature is used as follows in this paper: XXYYZZ

Where:

$\mathrm{XX}$ : indicates the type of $\mathrm{HMC}^{+} \mathrm{CS}$

YY: indicates the loading of $50 \%(\mathrm{w} / \mathrm{v})$ of OVA in relation to chitosan.

ZZ: indicates $10 \%$ of Quil-A (w/w) in relation to the loaded OVA.

In the following, the formulations are then phrased as either 705010, 855010 and 905010.

Particles without OVA and Quil-A are entitled blank XX chitosan particles. 


\section{Parameters for the Electrospraying Process}

Each of the prepared chitosan solutions were electrosprayed using a flow rate of 11.5 or $16.4 \mu \mathrm{L} / \mathrm{min}$, and the distance from tip of needle to the collector was either 10 or $15 \mathrm{~cm}$. Furthermore, the voltage was set to $24 \mathrm{kV}$ and a needle-size of $19 \mathrm{G}$ was utilized. The relative humidity was kept at $20 \%$ during the electrospray process using a polycarbonate chamber, and the temperature was $18-20^{\circ} \mathrm{C}$. The needle was connected to a high-voltage direct-current power supply and the processed particles were collected horizontally on aluminum foil or a glass surface.

\section{Morphology of the Chitosan Particles}

The chitosan particles were collected on aluminum foil, mounted on aluminum stubs and sputter-coated with gold. This generated a thin film of a thickness of $2.4 \mathrm{~nm}$ using a Q150R Rotary-Pumped Sputter Coater from Fedelco S.L (East Sussex, United Kingdom) prior to visualization. The particles were imaged with a Scanning Electron Microscope (SEM) Quanta FEG 200 ESEM with an Everhart-Thornley Detector (Hillsboro, OR US), using a magnification of 10,000x and a voltage of $12 \mathrm{kV}$.

\section{Particle Size and Zeta Potential}

For investigating the size of the dispersed particles, dynamic light scattering (DLS) was used. In a concentration of $1 \mathrm{mg} / \mathrm{mL}$, particles were dispersed in $20 \mathrm{mM}$ phosphate buffer at pH 7.4 and measured using a zetasizer Nano ZS (Malvern Instruments, Malvern, UK). The zetasizer was further also used for measuring the zeta potential of the dispersed particles in a concentration of $1 \mathrm{mg} / \mathrm{mL}$ in milliQ water.

\section{Stability of The Particles}

Stability of the particles was measured for $2 \mathrm{~h}$ utilizing DLS. The particles were dispersed in a concentration of $1 \mathrm{mg} / \mathrm{mL}$ in $10 \mathrm{mM}$ phosphate buffer at $\mathrm{pH}$ 7.4. At time 0,1 and $2 \mathrm{~h}$ the size of the particles were measured in duplicates or triplicates using a zetasizer Nano ZS.

\section{Encapsulation Efficiency and Release of OVA in the Chitosan Particles}

For release and encapsulation efficiency studies, fluorescein-labelled OVA (FITC-OVA) were utilized. FITCOVA was prepared according to the protocol described by Könnings et al.(25). The chitosan particles loaded with FITC-OVA, as well as with or without Quil-A, were prepared in the same way as described above.

The encapsulation efficiency was performed by dissolving $0.5 \mathrm{mg} / \mathrm{mL}$ of particles in $10 \%(\mathrm{v} / \mathrm{v})$ acetic acid solution. The particles were vortexed until fully dissolved and the fluorescence was measured using an excitation of $490 \mathrm{~nm}$ and an emission of $525 \mathrm{~nm}$ on a plate reader (Thermo Scientific Varioskan LUX plate Reader, Vantaa, Finland). Blank particles and acetic acid solution were used as controls.

Regarding the release studies, for time zero, particles were dispersed in $20 \mathrm{mM} \mathrm{PBS}, \mathrm{pH} 6.8$ at $37^{\circ} \mathrm{C}$ to reach a concentration of $1.33 \mathrm{mg} / \mathrm{mL}$. After addition of the buffer, $150 \mu \mathrm{L}$ of supernatant were instantly collected in a 96-well plate and its fluorescence was measured under the same settings as for measuring encapsulation efficiency. For the rest of the time points $(15,30,45,60,90 \mathrm{~min}$ and 2, 4, 6, 8, 24, 48 and 72 h), $200 \mu \mathrm{g}$ of particles were deposited inside each well and $150 \mu \mathrm{L}$ of $20 \mathrm{mM}$ PBS pH 6.8 at $37^{\circ} \mathrm{C}$ (final concentration of $1.33 \mathrm{mg} / \mathrm{mL}$ ) was added. The 96 -well plate was incubated at $37^{\circ} \mathrm{C}$ and the fluorescence was measured at each time point. Quil-A and PBS were used as controls. 
For both studies, the experiments were performed in triplicates.

\section{Mucoadhesion of the Chitosan Particles}

The mucoadhesion was tested using a Periodic Acid Schiff (PAS) assay described in the literature(26,27). 5 $\mathrm{mg} / \mathrm{mL}$ particles were dispersed in a solution of $0.025 \% \mathrm{w} / \mathrm{v}$ mucin in $0.1 \mathrm{M} \mathrm{PBS}$ at $\mathrm{pH} 6.5$ and vortexed for $2 \mathrm{~h}$ at $37^{\circ} \mathrm{C}$. The samples were centrifuged at $12,000 \mathrm{rpm}$ for $2 \mathrm{~min}$ and $25 \mu \mathrm{L}$ of the supernatant (unbounded mucin) was mixed in a 96-well plate with $120 \mu \mathrm{L}$ of $0.06 \% \mathrm{w} / \mathrm{v}$ periodic acid in $7 \% \mathrm{v} / \mathrm{v}$ AA and incubated for $1.5 \mathrm{~h}$ at $37^{\circ} \mathrm{C}$. Subsequently, at room temperature, $100 \mu \mathrm{L}$ of Schiff's reagent was added to the 96-well plate and incubated for $40 \mathrm{~min}$. The absorbance was read at $550 \mathrm{~nm}$ and correlated with a standard curve with mucin solutions. The assay was analyzed in a Thermo Scientific Varioskan LUXplate reader at $550 \mathrm{~nm}$ and performed in triplicates.

The unbounded mucin was calculated as follows:

$$
\% \text { Unbound mucin }=\left(\text { Mucin }_{\text {final }}\right) /\left(\text { Mucin }_{\text {initial }}\right) * 100
$$

Where, mucin $_{\text {final }}$ was calculated from the standard curve.

\section{Cytotoxicity of the Particles}

THP-1 (human monocytic cell line) was purchased from Deutsche Sammlung von Mikroorganismen und Zellkulturen (DSMZ) (Braunschweig, Germany). The cells were grown in T75 flasks in RPMI 1640 supplemented with $10 \% \mathrm{FBS}$ and $1 \%$ penicillin/streptomycin and maintained at $37^{\circ} \mathrm{C}$ and $5 \% \mathrm{CO}_{2}$. For differentiating the THP-1 cells into macrophage-like cells, $5 \mathrm{ng} / \mathrm{mL}$ PMA was added to the cell culture medium. After two days, the differentiated THP-1 cells were stained with VyBrant ${ }^{\mathrm{TM}}$ CFDA SE Cell Tracer according to the protocol from the manufacturer. Subsequently, the cells were harvested and used for the cytotoxicity studies.

The harvested cells were seeded in a 96 well plate with 15,000 cells per well in the THP-1 medium (described previously in this section), and was allowed to attach to the well overnight at $37^{\circ} \mathrm{C}$ and $5 \% \mathrm{CO}_{2}$. The following day, the chitosan particles were added to the cells in a concentration of $4 \mathrm{mg} / \mathrm{mL}$ in RPMI medium without phenol red, and as controls triton X-100 (2\% (v/v)) were also incubated with the cells. The formulations and the control were incubated for $24 \mathrm{~h}$ at $37^{\circ} \mathrm{C}$ and $5 \% \mathrm{CO}_{2}$ with a rotation of $100 \mathrm{rpm}$. After $24 \mathrm{~h}$, the cells were washed and fixed with $16 \%$ of PFA, and imaged in a fluorescence microscope at excitation of $492 \mathrm{~nm}$ and emission of $517 \mathrm{~nm}$.

\section{Statistical analysis}

The data are expressed as mean \pm standard deviation (SD). Where appropriate, statistical analysis were carried out using Student t-tests using GraphPad Prism 7.03 (La Jolla, CA, USA). P-values below 5 \% ( $p$ $<0.05$ ) were considered statistically significant.

\section{RESULTS AND DISCUSSION}

\section{Morphology, size and zeta potential}

Chitosan has been proven as a promising carrier in oral vaccination(9). When utilizing electrospray for the preparation of the chitosan particles optimization is needed. Previously, the three chitosan types of $\mathrm{HMC}^{+}$ $(70,85$ and 90$)$ have been optimized in terms of forming chitosan stable microparticles(24). It has been an area of focus to investigate which of the three chitosan types would be most suited for the purpose of oral vaccination. Furthermore, for this study, OVA and Quil-A were included in the formulation and therefore, 
minor optimization steps were again necessary. OVA is a protein and was chosen as a model for subunit antigens as it is inexpensive and easy available. Quil-A is one of many existing adjuvants, but was selected here as it is well tolerated orally(28). It is inexpensive and obtained by purification of an extract from the bark of the Chilean tree Quillaja saponaria Molina(29). Quil-A has previously been combined with particulates and OVA for oral vaccine delivery where immune responses were observed(30,31).

The size, charge and morphology of the particulate vaccine formulations will have great impact on their performance as a vaccine(32), and therefore this is of course of great importance to investigate.

The size of the particles, when dispersed in buffer, was measured using DLS (Table I). It was observed that the blank particles had significant different sizes with $0.45 \pm 0.18 \mu \mathrm{m}$ for blank $\mathrm{HMC}^{+} 85$, and $1.37 \pm 0.35 \mu \mathrm{m}$ and $2.43 \pm 0.23 \mu \mathrm{m}$ for blank $\mathrm{HMC}^{+} 70$ and blank $\mathrm{HMC}^{+} 90$, respectively ( $\mathrm{p}$-value of 0.0004). When encapsulating OVA and Quil-A, the sizes increased substantially, and here 705010 was found to have a size of $4.60 \pm 0.77 \mu \mathrm{m}$, whereas it was determined to be $5.78 \pm 0.63 \mu \mathrm{m}$ and $7.47 \pm 1.64 \mu \mathrm{m}$ for 901050 and 851050, respectively. There was no significant difference in the size for the three formulations ( $p$-value of 0.537). It is difficult to define the optimal size for a vaccine formulation, but antigen presenting cells have been reported to process particles in the size range from $20 \mathrm{~nm}$ to $3 \mu \mathrm{m}$. Although, microparticles with a size up to $20 \mu \mathrm{m}$ has been reported as efficient for vaccine delivery(32). The polydispersity index (PDI) was high for all the samples indicating that the particle sizes were not very uniform. This is also indicated on the SEM images (Fig. 1) for all the samples, both the blank and the ones encapsulating OVA and Quil-A. The particles from samples 705010 and 905010 are spherical with a smooth surface, whereas the particles in 855010 have an unsmooth surface.

The zeta potential is a parameter of high relevance for oral delivery as it can predict the interaction between the small intestine and particulates. Positive-charged particles can be beneficial, for uptake in the intestine, as they can bind to the negative charged intestinal cell membranes(33). It has been reported that particles with a zeta potential above $30 \mathrm{mV}$ have good stability in aqueous medium and greater than $60 \mathrm{mV}$ the particles can be considered to have an excellent stability(33). In Table I, it can be observed that the zeta potential for all the particles is positive. It can also further be seen that OVA and Quil-A have a stabilizing effect on the chitosan particles as the zeta potential increased when adding the two components. There is no significant difference ( $p$-value of 0.2204 ) between the zeta potential for 705010 and 855010 , whereas the zeta potential of $74.84 \pm 2.29 \mathrm{mV}$ for 901050 indicated a very high stability of this sample.

Table I. Size, PDI and zeta potential of the chitosan particles, blank and with OVA and Quil-A. The data represents mean \pm SD in triplicates.

\begin{tabular}{llll}
\hline Name & Size $(\boldsymbol{\mu m})$ & PDI & Zeta potential $(\mathbf{m V})$ \\
\hline Blank HMC +70 & $1.37 \pm 0.35$ & $0.75 \pm 0.16$ & $+9.42 \pm 0.38$ \\
705010 & $4.66 \pm 0.77$ & $0.44 \pm 0.48$ & $+45.94 \pm 2.42$ \\
Blank HMC +85 & $0.45 \pm 0.18$ & $0.61 \pm 0.09$ & $+23.04 \pm 1.11$ \\
855010 & $7.47 \pm 1.64$ & $0.62 \pm 0.05$ & $+49.5 \pm 3.51$ \\
Blank HMC +90 & $2.43 \pm 0.23$ & $0.76 \pm 0.32$ & $+24.0 \pm 3.61$ \\
901050 & $5.78 \pm 0.63$ & $0.86 \pm 0.24$ & $+74.84 \pm 2.29$ \\
\hline
\end{tabular}



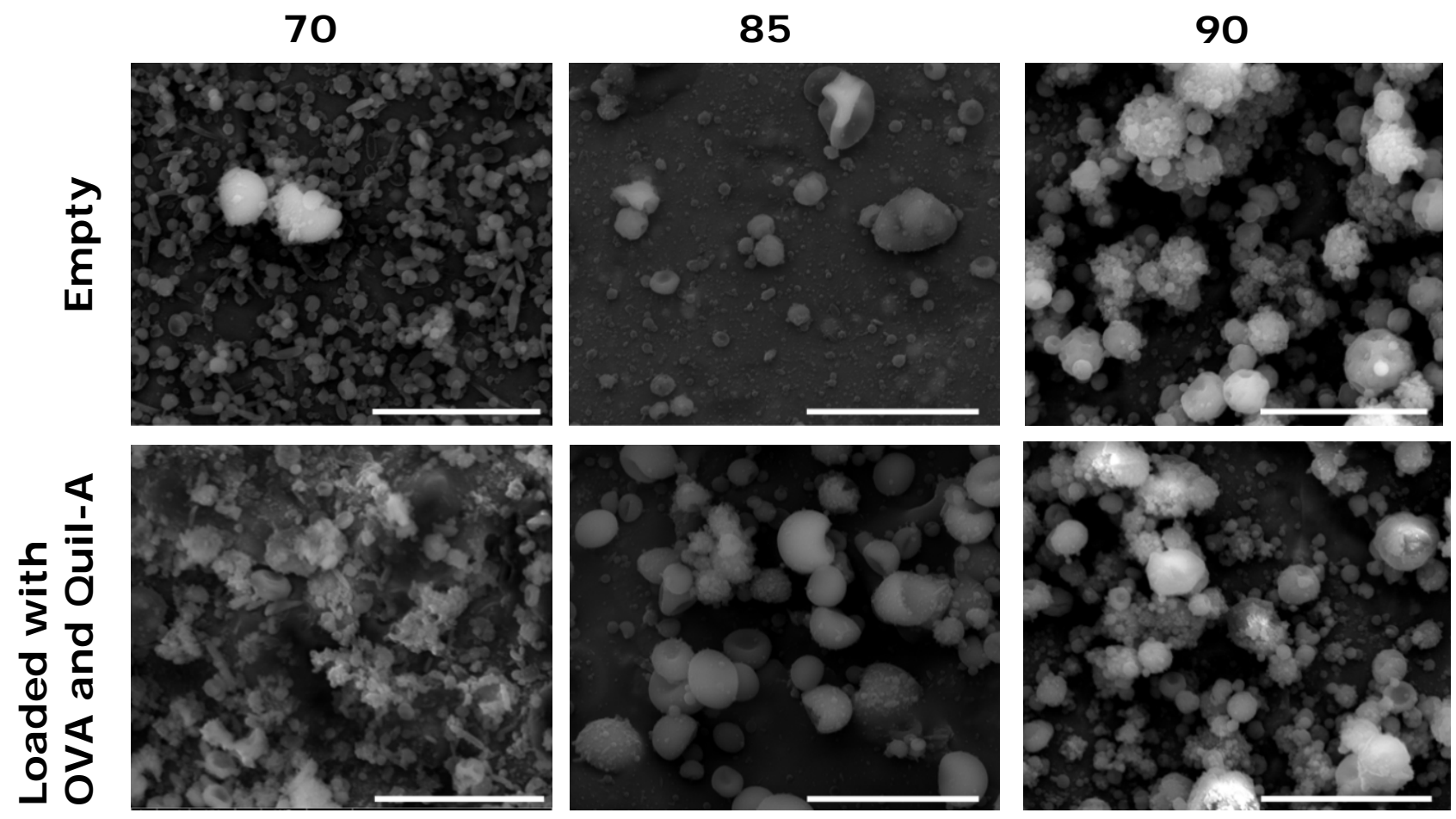

Fig. 1. SEM images of particles investigated with a magnification of 10,000x and the scale bars represent 5 $\mu \mathrm{m}$ on all the images.

\section{Stability of the chitosan particles}

Stability of the electrosprayed chitosan particles was measured over $2 \mathrm{~h}$ in buffer and the size was investigated using DLS. The stability after 1 and $2 \mathrm{~h}$ was calculated in relation to the initial size of the particles (Fig. 2). For the blank $\mathrm{HMC}^{+} 70$ and 705010 chitosan particles, the size increased after $1 \mathrm{~h}$, whereas after $2 \mathrm{~h}$ the size was closer to the initial size with no significant difference ( $p$-values of 0.2890 and 0.1376 for blank $\mathrm{HMC}^{+} 70$ and 705010 particles, respectively). The same phenomenon was observed for the blank $\mathrm{HMC}^{+} 85$ and blank $\mathrm{HMC}^{+} 90$ chitosan particles, but for the ones encapsulating OVA and Quil-A, the particle size increases dramatically up to 730 and 893 \% compared to the initial size for 855010 and 905010 , respectively. This indicates aggregation of the particles which is commonly observed for these types of particles(34). From the above, it can be detected that OVA and Quil-A had a non-stabilizing effect on the particles, except for 705010 sample. These particles were concluded to be the most stable during the $2 \mathrm{~h}$. It can also be stated that these stability observations do not correspond well with the zeta potential measurements where the $\mathrm{HMC}^{+} 90$ formulations should appear to be the ones with the highest stability. 


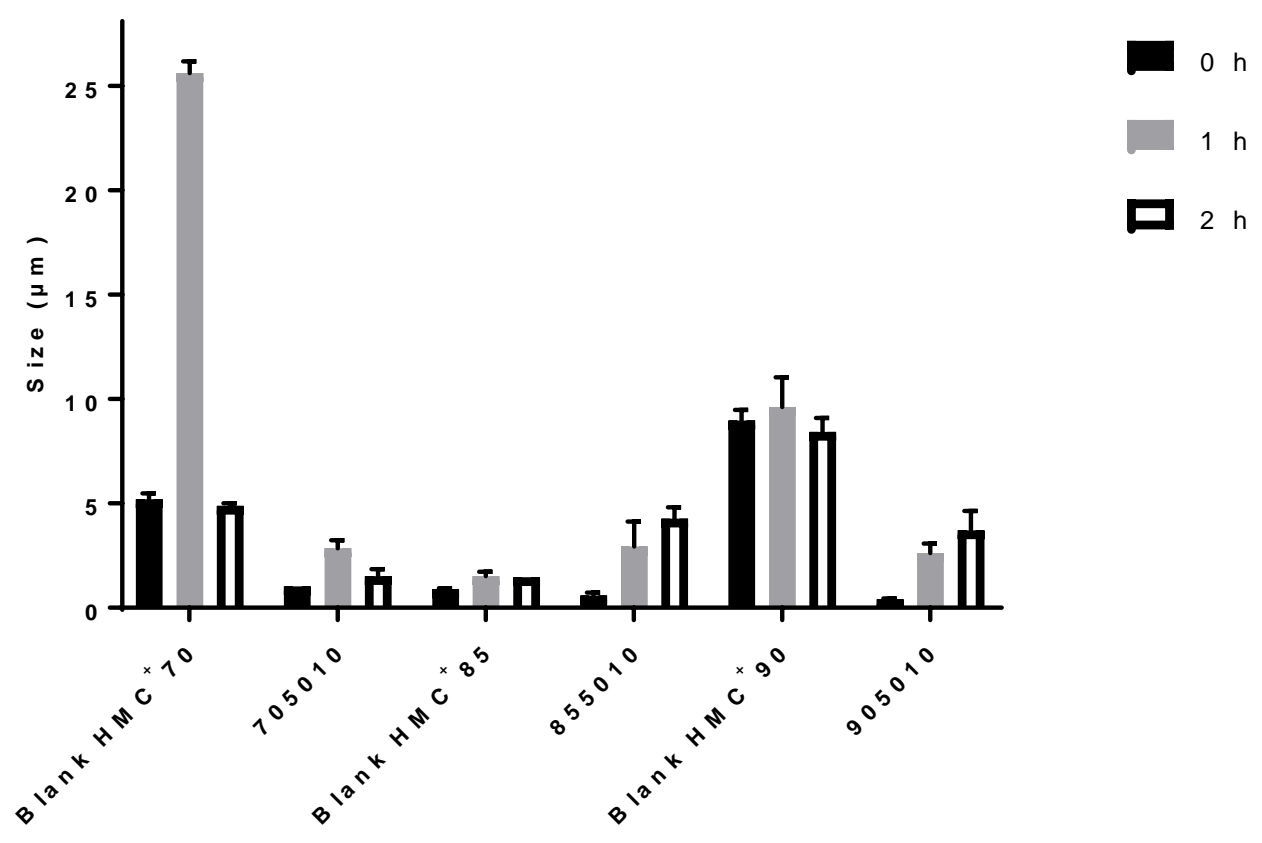

Fig. 2. Stability of the particles over $2 \mathrm{~h}$ in PBS at pH 7.4 measured by DLS. The data represents mean \pm SD in triplicates.

\section{Encapsulation efficiency and release of OVA}

For particles for oral vaccine delivery, it is essential to encapsulate high antigen content; this is often where oral vaccine formulations fail as the antigen concentration is not sufficiently high to obtain an immune response(35). In the present study, $50 \%$ of OVA in relation to $3 \%(\mathrm{w} / \mathrm{v})$ chitosan was used in order to have a high antigen concentration. The concentration of Quil-A was based on previous studies found in the literature where $10 \%(\mathrm{w} / \mathrm{w})$ Quil-A in relation to OVA resulted in good in vivo immune responses(36,37). It is important to investigate how much OVA there is encapsulated into the particles(38). From the encapsulation efficiency (Fig. 3), it can be observed that above $80 \%$ of the OVA was encapsulated into the particles. The efficiency for 705010 and 855010 was, for both, $87 \%$, whereas it was $82 \%$ for 905010 . These high ratios of encapsulated OVA were expected, making electrospraying a promising encapsulation technique due to its high encapsulation efficiency(39). Moreover, a high encapsulation efficiency means that a low portion of the active compound was lost during manufacturing also resulting in important economic profit(38). In the literature, high drug encapsulations of approximately $90 \%$ have previously been reported showing high efficiency using electrospraying $(19,39,40)$. OVA has previously been encapsulated in calcium-alginate microparticles prepared by electrospray and the maximum encapsulation efficiency was found to be $41 \%$ of OVA(23) hence, the efficiency is also highly dependent on the polymer used as carrier material. 


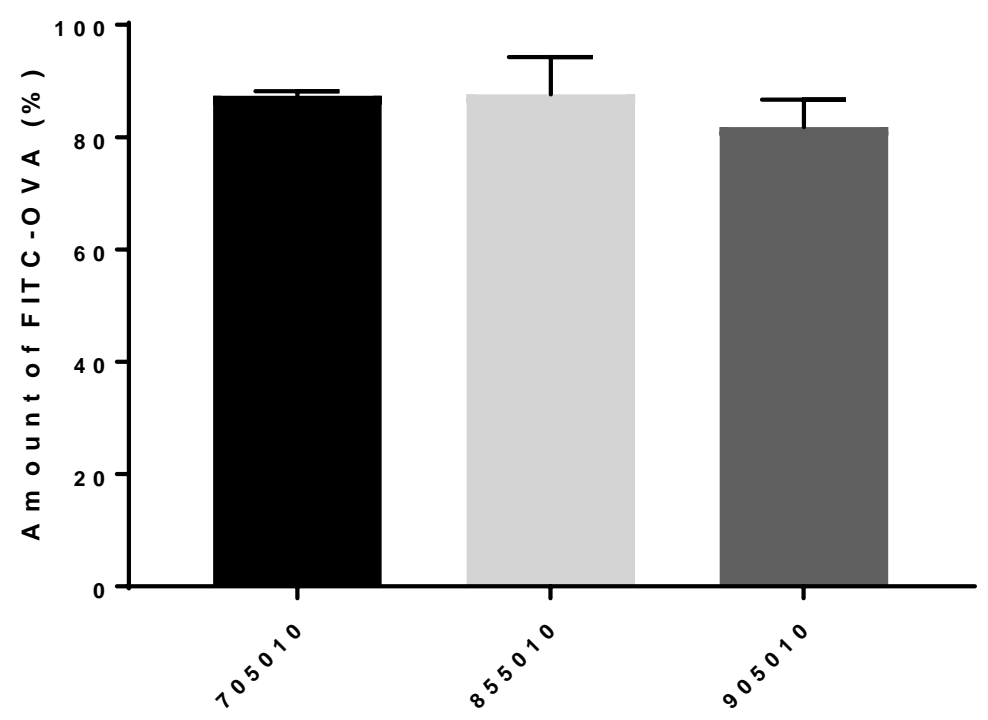

Fig. 3. Encapsulation efficiency of FITC-OVA into the chitosan particles produced by the electrospraying process. Graph represents mean \pm SD in triplicates.

The release of FITC-labeled OVA from the chitosan particles was investigated in PBS at pH 6.8. It can be observed that there was no significant difference ( $p$-value of 0.1742 ) in the release of OVA from the three chitosan formulations (Fig. 4). For all the formulations, 38-47 \% of OVA was released within a timeframe of $72 \mathrm{~h}$. A substantial part of the OVA was released within the first $6 \mathrm{~h}$, also with a large fraction released in a burst fashion, but still some sustained release was found. The sustained release can be of great importance when developing vaccine formulations(41). In the literature, chitosan nanoparticles have frequently been manufactured for vaccine delivery and e.g. in a paper by Gordon et al. the FITC-OVA released from chitosan nanoparticles was approximately $10 \%$ after one day and after 10 days the release was found to be $50 \%$ of the encapsulated FITC-OVA(42). In another study, it was found that OVA released from chitosan microparticles was $10 \%$ within $60 \mathrm{~min}$ and after further $180 \mathrm{~min}$ no more OVA was released(43). These studies confirm that a $100 \%$ release cannot be expected from chitosan particles. Moreover, it could also be speculated that there is an interaction between chitosan and OVA retaining the release of OVA even further. 


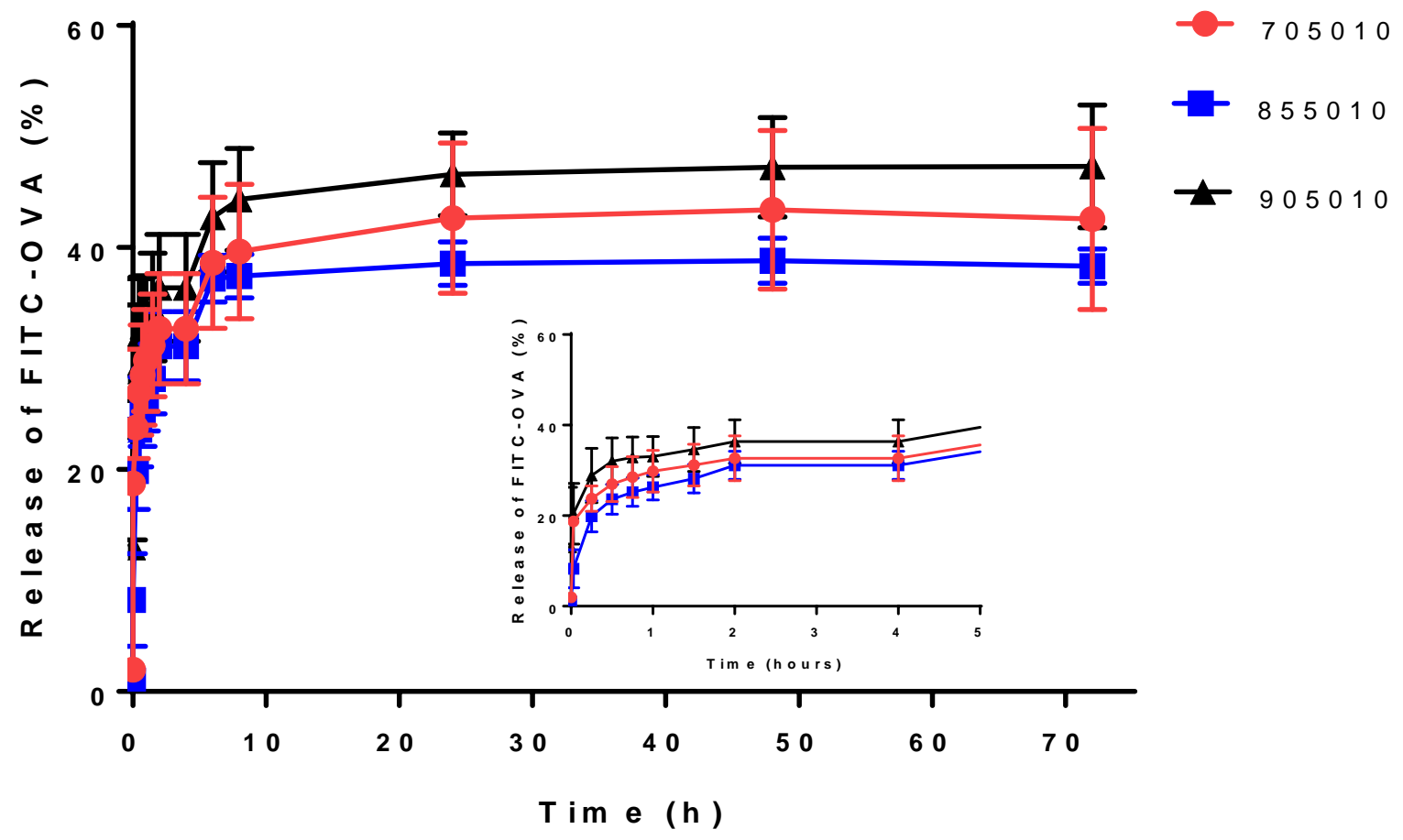

Fig. 4. Release profiles of FITC-OVA from the chitosan particles, 705010, 855010 and 905010 . The release of OVA was performed in PBS at pH 6.5 for $80 \mathrm{~h}$. The insert shows the release for the first $5 \mathrm{~h}$. The profiles represent mean \pm SD in triplicates.

\section{Mucoadhesion}

Another major factor for oral vaccine delivery to succeed is the interaction of the particles with the mucus in the small intestine(2). This will often be occurring through electrostatic interaction between a positive surface charge on the particle (as chitosan) and the negatively charged sialic acid group of mucin(2). This process of mucoadhesion can both be beneficial and disadvantageous for vaccine delivery, as the increase in residence time could allow greater chance of particle uptake. It could also result in the formulation becoming potentially trapped within the loosely adherent mucus layer and being at greater risk of clearance due to mucociliary action $(44,45)$. There are several methods to test for mucoadhesion as e.g. texture analyzer, atomic force microscopy (AFM) and rheometer, but also colorimetric assays are often used(46). The PAS assay is such a colorimetric technique which is widely used for quantitative and qualitative analysis of mucoadhesion(27). It measures the amount of unbound mucin meaning that a low value is a measure of high mucoadhesion.

Fig. 5 shows the percentage of unbounded mucin after incubation of mucin and the chitosan particles, and it can be observed that all the samples do not seem to show high mucoadhesive properties. It was expected that the higher DD of chitosan it should have a clear effect on a higher mucoadhesion of particles, due to more $-\mathrm{NH}_{2}$ groups available to interact with the mucus(47). From the results in this study, no clear trends were observed. In the two cases of $\mathrm{HMC}^{+} 85$ and $\mathrm{HMC}^{+} 90$ chitosan particles, the loading of OVA and Quil-A made the particles less mucoadhesive. This is unexpected as the zeta potential was higher in these two cases (Table I). It is unclear from the literature if particles should have mucoadhesive properties for succeed 
in oral vaccine delivery. Considering that the mucus covering the M-Cells is a thin layer, it could be assumed that the two formulations of 705010 and 855010 are sufficient mucoadhesive to be taken up by the M-cells before being flushed away.

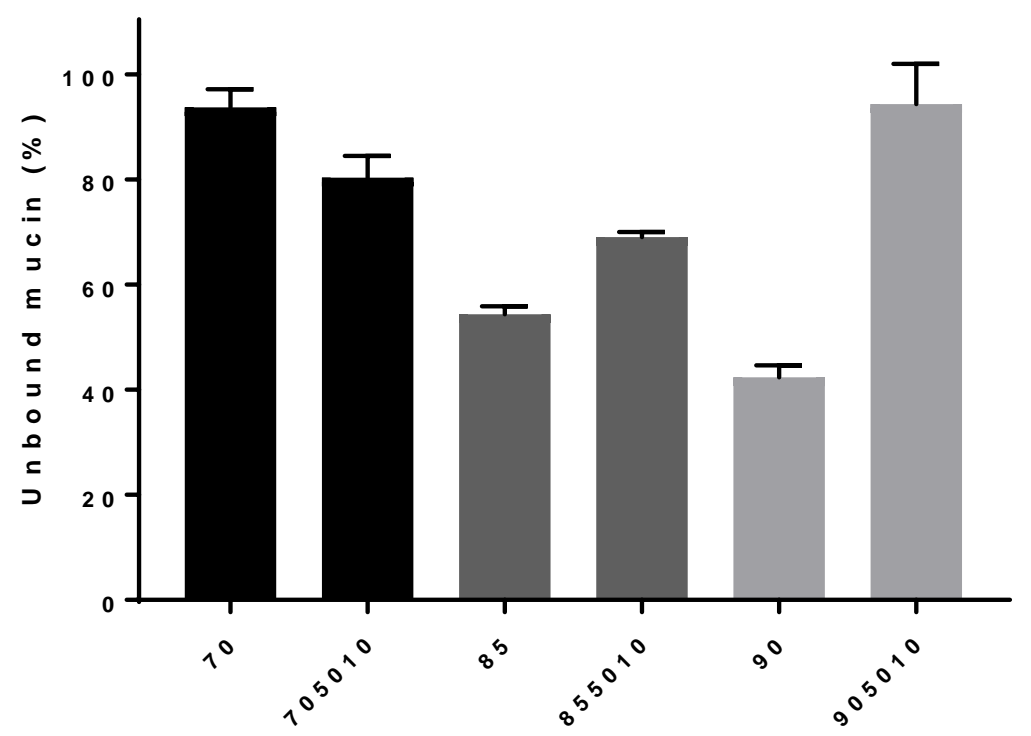

Fig. 5. Mucoadhesion of the chitosan particles (705010, 855010 and 905010 and their blanks) investigated by the PAS assay. The graph represents mean \pm SD in triplicates.

\section{Cytotoxicity}

Even though chitosan is regarded as biocompatible and a safe compound, it is important to evaluate the cytotoxicity of the developed formulations(48). For vaccine systems, differentiated THP-1 cells (human leukemia cell line) can be used to evaluate the cytotoxicity of the formulations(49). Due to instability of the $\mathrm{HMC}^{+} 85$ chitosan formulation this was not tested here for the cytotoxicity.

It can be observed that the $\mathrm{HMC}^{+} 90$ chitosan formulation was slightly more cytotoxic than the $\mathrm{HMC}^{+} 70$ formulation with $26.5 \%$ and $14.3 \%$, respectively, but no significant difference ( $p$-value: 0.8415 ) was found (Fig. 6). The highest value was found for the 905010 with $26.5 \%$ compared to the positive control, and the lowest value was found for the 705010 with only $8 \%$ dead cells compared to the control. Therefore, it is indicated by these studies that the electrosprayed chitosan formulations did not exhibit cytotoxicity. In the literature, many cytotoxicity studies have been performed on oral drug formulations looking at Caco-2 cell viability. From these studies, it has been found that chitosan has a tendency to decrease the viability of Caco- 2 cells and it is suggested to be due to electrostatic interactions between the chitosan particles and the cell membrane $(50,51)$. The vaccine formulations need to be taken up by the M-cells and transported to the immune cells(3) hence, they will not interact with the intestinal epithelium in the same way as drug formulations developed for oral delivery. 


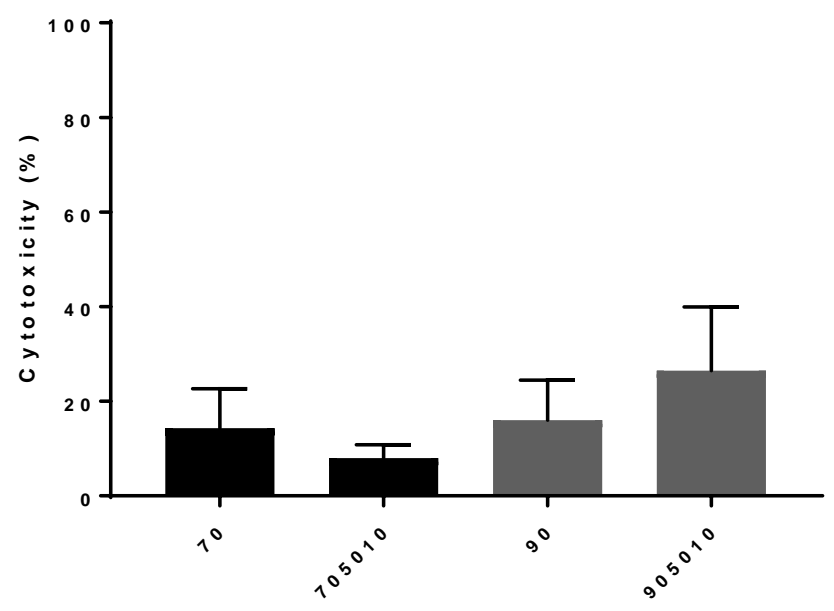

Fig. 6. Cytotoxicity of blank $\mathrm{HMC}^{+} 70,705010$, blank $\mathrm{HMC}^{+} 90$ and 905010 incubated for $24 \mathrm{~h}$ together with THP-1 cells and the LDH level was measured. The cytotoxicity was calculated as percentage in relation to $100 \%$ dead cells (measured with triton X-100). The graph represents mean \pm SD in triplicates.

\section{CONCLUSION}

Here, we present the development and in vitro characterization of a complete vaccine formulation consisting of chitosan microparticles encapsulated with OVA and Quil-A prepared by electrospray. Three different chitosan's were tested $\left(\mathrm{HMC}^{+} 70, \mathrm{HMC}^{+} 85\right.$ and $\left.\mathrm{HMC}^{+} 90\right)$ and encapsulated with $50 \%$ OVA and 10 \% Quil-A. The formulation 705010 showed to be the most promising as an oral vaccine system due to low cytotoxicity and high particle stability in buffer solution. For the future, this will be investigated for its potential as an oral vaccine formulation by testing it in vivo in mice.

\section{ACKNOWLEDGEMENTS}

The Danish National Research Foundation (Project DNRF122) and Villum Foundation's Center (Grant No. 9301) for Intelligent Drug Delivery and Sensing Using Microcontainers and Nanomechanics (IDUN) is acknowledged. Line Hagner Nielsen would in addition like to thank the Danish Research Council for Technology and Production (FTP), Project DFF-4004-00120B, for financial support. Furthermore, the European Union's Seventh Framework Programme for research, technological development and demonstration under grant agreement $n^{\circ} 613931$ is thanked for financial support. Furthermore, Jorge Alberto $S$. Moreno would like to acknowledge the financial support from the Consejo Nacional de Ciencia y Tecnología (CONACYT) and the Instituto de Innovación y Transferencia de Tecnología (I2T2).

\section{REFERENCES}

1. Foged C. Subunit vaccines of the future: the need for safe, customized and optimized particulate delivery systems. Ther Deliv [Internet]. 2011;2(8):1057-77. Available from: http://www.ncbi.nlm.nih.gov/pubmed/22826868

2. Gebril A, Alsaadi M, Acevedo R, Mullen AB, Ferro VA. Optimizing efficacy of mucosal vaccines. Expert Rev Vaccines [Internet]. 2012;11(9):1139-55. Available from: http://informahealthcare.com/doi/abs/10.1586/erv.12.81\%5Cnhttp://www.ncbi.nlm.nih.gov/pubm ed/23151169

3. Davitt $\mathrm{CJH}$, Lavelle EC. Delivery strategies to enhance oral vaccination against enteric infections. Adv Drug Deliv Rev [Internet]. 2015;91:52-69. Available from: 
http://www.ncbi.nlm.nih.gov/pubmed/25817337

4. Rizwan SB, McBurney WT, Young K, Hanley T, Boyd BJ, Rades T, et al. Cubosomes containing the adjuvants imiquimod and monophosphoryl lipid $A$ stimulate robust cellular and humoral immune responses. J Control Release [Internet]. 2013;165(1):16-21. Available from: http://dx.doi.org/10.1016/j.jconrel.2012.10.020

5. Wack A, Rappuoli R. Vaccinology at the beginning of the 21st century. Curr Opin Immunol. 2005;17(4 SPEC. ISS.):411-8.

6. Fujkuyama Y, Tokuhara D, Kataoka K, Gilbert RS, McGhee JR, Yuki Y, et al. Novel vaccine development strategies for inducing mucosal immunity. Expert Rev Vaccines [Internet]. 2012;11(3):367-79. Available from: http://www.pubmedcentral.nih.gov/articlerender.fcgi?artid=3315788\&tool=pmcentrez\&rendertype $=$ abstract

7. Mishra N, Goyal AK, Tiwari S, Paliwal R, Paliwal SR, Vaidya B, et al. Recent advances in mucosal delivery of vaccines: role of mucoadhesive/biodegradable polymeric carriers. Expert Opin Ther Pat [Internet]. 2010;20(5):661-79. Available from: http://www.ncbi.nlm.nih.gov/pubmed/20345332

8. des Rieux A, Fievez V, Garinot M, Schneider YJ, Preat V. Nanoparticles as potential oral delivery systems of proteins and vaccines: A mechanistic approach. J Control Release. 2006;116(1):1-27.

9. Van der Lubben IM, Verhoef JC, Borchard G, Junginger HE. Chitosan for mucosal vaccination. Adv Drug Deliv Rev. 2001;52(2):139-44.

10. Singh B, Maharjan S, Cho KH, Cui LH, Park IK, Choi YJ, et al. Chitosan-based particulate systems for the delivery of mucosal vaccines against infectious diseases. Int J Biol Macromol [Internet]. 2018;110:54-64. Available from: http://dx.doi.org/10.1016/j.ijbiomac.2017.10.101

11. Rinaudo M. Chitin and chitosan: Properties and applications. Prog Polym Sci. 2006;31:603-32.

12. Illum L, Jabbal-Gill I, Hinchcliffe M, Fisher AN, Davis SS. Chitosan as a novel nasal delivery system for vaccines. Adv Drug Deliv Rev. 2001;51(1-3):81-96.

13. Nishimura K, Nishimura S ichiro, Nishi N, Numata F, Tone $\mathrm{Y}$, Tokura S, et al. Adjuvant activity of chitin derivatives in mice and guinea-pigs. Vaccine. 1985;3(5):379-84.

14. Ahmed TA, Aljaeid BM. Preparation, characterization, and potential application of chitosan, chitosan derivatives, and chitosan metal nanoparticles in pharmaceutical drug delivery. Drug Des Devel Ther. 2016;10:483-507.

15. Zamani M, Prabhakaran MP, Ramakrishna S. Advances in drug delivery via electrospun and electrosprayed nanomaterials. Int J Nanomedicine. 2013;8:2997-3017.

16. García-Moreno PJ, Özdemir N, Stephansen K, Mateiu R V., Echegoyen Y, Lagaron JM, et al. Development of carbohydrate-based nano-microstructures loaded with fish oil by using electrohydrodynamic processing. Food Hydrocoll. 2017;69:273-85.

17. Xie J, Wang $\mathrm{C}-\mathrm{H}$. Encapsulation of proteins in biodegradable polymeric microparticles using electrospray in the Taylor cone-jet mode. Biotechnol Bioeng [Internet]. 2007 Aug 1 [cited 2016 Jun 24];97(5):1278-90. Available from: http://doi.wiley.com/10.1002/bit.21334

18. Gallovic MD, Schully KL, Bell MG, Elberson MA, Palmer JR, Darko CA, et al. Acetalated Dextran Microparticulate Vaccine Formulated via Coaxial Electrospray Preserves Toxin Neutralization and Enhances Murine Survival Following Inhalational Bacillus Anthracis Exposure. Adv Healthc Mater. 2016;5(20):2617-27.

19. Lee Y-H, Mei F, Bai M-Y, Zhao S, Chen D-R. Release profile characteristics of biodegradable-polymercoated drug particles fabricated by dual-capillary electrospray. J Control Release. 2010;145:58-65.

20. Arya N, Chakraborty S, Dube N, Katti DS. Electrospraying: A Facile Technique for Synthesis of Chitosan-Based Micro/Nanospheres for Drug Delivery Applications. J Biomed Mater Res Part Bapplied Biomater. 2009;88B(1):17-33.

21. Junkins RD, Gallovic MD, Johnson BM, Collier MA, Watkins-Schulz R, Cheng N, et al. A robust microparticle platform for a STING-targeted adjuvant that enhances both humoral and cellular immunity during vaccination. J Control Release [Internet]. 2018;270(February 2017):1-13. Available 
from: http://linkinghub.elsevier.com/retrieve/pii/S016836591731026X

22. Suksamran T, Opanasopit P, Rojanarata T, Ngawhirunpat T, Ruktanonchai U, Supaphol P. Biodegradable alginate microparticles developed by electrohydrodynamic spraying techniques for oral delivery of protein. J Microencapsul. 2009;26(7):563-70.

23. Suksamran $T$, Ngawhirunpat $T$, Rojanarata $T$, Sajomsang $W$, Pitaksuteepong $T$, Opanasopit P. Methylated N-(4-N,N-dimethylaminocinnamyl) chitosan-coated electrospray OVA-loaded microparticles for oral vaccination. Int J Pharm [Internet]. 2013;448(1):19-27. Available from: http://dx.doi.org/10.1016/j.ijpharm.2013.03.015

24. Moreno JAS, Mendes AC, Stephansen K, Engwer C, Goycoolea FM, Boisen A, et al. Development of electrosprayed mucoadhesive chitosan microparticles. Carbohydr Polym. 2018;190:240-7.

25. Konnings S, Copland MJ, Davies NM, Rades T. A method for the incorporation of ovalbumin into immune stimulating complexes prepared by the hydration method. Int J Pharm. 2002;241(2):385-9.

26. Mantle $M$, Allen A. A colorimetric assay for glycoproteins based on the periodic acid/Schiff stain. Biochem Soc Trans. 1978;6(3):607-9.

27. Kilcoyne M, Gerlach JQ, Farrell MP, Bhavanandan VP, Joshi L. Periodic acid-Schiff's reagent assay for carbohydrates in a microtiter plate format. Anal Biochem. 2011;416:18-26.

28. Sjölander A, Cox JC. Uptake and adjuvant activity of orally delivered saponin and ISCOM(TM) vaccines. Adv Drug Deliv Rev. 1998;34(2-3):321-38.

29. Kensil C, Wu J, Soltysik S. Structural and immunological characterization of the vaccine adjuvant QS21. Pharm Biotechnol. 1995;6:525-41.

30. von Halling Laier C, Gibson B, van de Weert M, Boyd BJ, Rades T, Boisen A, et al. Spray dried cubosomes with ovalbumin and Quil-A as a nanoparticulate dry powder vaccine formulation. Int J Pharm [Internet]. 2018;550:35-44. Available from: https://www.sciencedirect.com/science/article/pii/S0378517318306148?via\%3Dihub

31. Mcl Mowat A, Smith RE, Donachie AM, Furrie E, Grdic D, Lycke N. Oral vaccination with immune stimulating complexes. Immunol Lett. 1999;65(1-2):133-40.

32. Bachmann MF, Jennings GT. Vaccine delivery: a matter of size, geometry, kinetics and molecular patterns. Nat Rev Immunol [Internet]. 2010;10(11):787-96. Available from: http://www.ncbi.nlm.nih.gov/pubmed/20948547

33. Honary S, Zahir F. Effect of Zeta Potential on the Properties of Nano-Drug Delivery Systems -A Review (Part 2). Trop J Pharm Res April J Cit ReportsScience Ed [Internet]. 2013 [cited 2016 Jun 24];12(122):265-265. Available from: http://www.tjpr.org

34. Jiang L, Duan H, Ji X, Wang T, Wang Y, Qiu J. Application of a simple desolvation method to increase the formation yield, physical stability and hydrophobic drug encapsulation capacity of chitosanbased nanoparticles. Int J Pharm [Internet]. 2018;545(1-2):117-27. Available from: http://linkinghub.elsevier.com/retrieve/pii/S0378517318301893

35. Vela Ramirez JE, Sharpe LA, Peppas NA. Current state and challenges in developing oral vaccines. Adv Drug Deliv Rev [Internet]. 2017;114:116-31. Available from: http://dx.doi.org/10.1016/j.addr.2017.04.008

36. Aguila A, Donachie AM, Peyre M, McSharry CP, Sesardic D, Mowat AM. Induction of protective and mucosal immunity against diphtheria by a immune stimulating complex (ISCOMS) based vaccine. Vaccine. 2006;24(24):5201-10.

37. Mowat AM, Donachie AM, Reid G, Jarrett O. Immune-stimulating complexes containing Quil A and protein antigen prime class I MHC-restricted T lymphocytes in vivo and are immunogenic by the oral route. Immunology [Internet]. 1991;72(3):317-22. Available from: http://www.pubmedcentral.nih.gov/articlerender.fcgi?artid=1384389\&tool=pmcentrez\&rendertype $=$ abstract

38. McClements DJ. Encapsulation, protection, and delivery of bioactive proteins and peptides using nanoparticle and microparticle systems: A review. Adv Colloid Interface Sci [Internet]. 2018;253:122. Available from: https://doi.org/10.1016/j.cis.2018.02.002 
39. Fukui Y, Maruyama T, Iwamatsu Y, Fujii A, Tanaka T, Ohmukai Y, et al. Colloids and Surfaces A : Physicochemical and Engineering Aspects Preparation of monodispersed polyelectrolyte microcapsules with high encapsulation efficiency by an electrospray technique. Colloids Surfaces $A$ Physicochem Eng Asp [Internet]. 2010;370(1-3):28-34. Available from: http://dx.doi.org/10.1016/j.colsurfa.2010.08.039

40. Nath SD, Son S, Sadiasa A, Min YK, Lee BT. Preparation and characterization of PLGA microspheres by the electrospraying method for delivering simvastatin for bone regeneration. Int J Pharm [Internet]. 2013;443(1-2):87-94. Available from: http://dx.doi.org/10.1016/j.ijpharm.2012.12.037

41. Myschik J, Eberhardt F, Rades T, Hook S. Immunostimulatory biodegradable implants containing the adjuvant Quil-A - Part I: Physicochemical characterisation. J Drug Target. 2008;16(3):213-23.

42. Gordon S, Saupe A, McBurney W, Rades T, Hook S. Comparison of chitosan nanoparticles and chitosan hydrogels for vaccine delivery. J Pharm Pharmacol. 2008;60(12):1591-600.

43. van der Lubben IM, Verhoef JC, van Aelst AC, Borchard G, Junginger HE. Chitosan microparticles for oral vaccination: preparation, characterization and preliminary in vivo uptake studies in murine Peyer's patches. Biomaterials. 2001;22(7):687-94.

44. Kaneko K, McDowell A, Ishii Y, Hook S. Characterization and evaluation of stabilized particulate formulations as therapeutic oral vaccines for allergy. J Liposome Res [Internet]. 2017;1-9. Available from: https://www.tandfonline.com/doi/full/10.1080/08982104.2017.1370472

45. Dhawan S, Singla AK, Sinha VR. Evaluation of mucoadhesive properties of chitosan microspheres prepared by different methods. AAPS PharmSciTech. 2004;5(4):e67.

46. Mackie AR, Goycoolea FM, Menchicchi B, Caramella CM, Saporito F, Lee S, et al. Innovative Methods and Applications in Mucoadhesion Research. Macromol Biosci. 2017;17(8):1-32.

47. Kumar A, Vimal A, Kumar A. Why Chitosan? From properties to perspective of mucosal drug delivery. Int J Biol Macromol [Internet]. 2016;91:615-22. Available from: http://dx.doi.org/10.1016/j.ijbiomac.2016.05.054

48. Loh JW, Saunders M, Lim LY. Cytotoxicity of monodispersed chitosan nanoparticles against the Caco2 cells. Toxicol Appl Pharmacol [Internet]. 2012;262(3):273-82. Available from: http://dx.doi.org/10.1016/j.taap.2012.04.037

49. Heuking S, Adam-Malpel S, Sublet E, lannitelli A, Stefano A Di, Borchard G. Stimulation of human macrophages (THP-1) using Toll-like receptor-2 (TLR-2) agonist decorated nanocarriers. J Drug Target. 2009;17(8):662-70.

50. Soliman GM, Zhang YL, Merle G, Cerruti M, Barralet J. Hydrocaffeic acid-chitosan nanoparticles with enhanced stability, mucoadhesion and permeation properties. Eur J Pharm Biopharm [Internet]. 2014;88(3):1026-37. Available from: http://dx.doi.org/10.1016/j.ejpb.2014.09.003

51. Loretz B, Bernkop-Schnürch A. In vitro cytotoxicity testing of non-thiolated and thiolated chitosan nanoparticles for oral gene delivery. Nanotoxicology. 2007;1(2):139-48. 